\title{
ANÁLISE ESTATISTICA E QUALITATIVA COM UTILIZACĀO DA MATRIZ GUT EM MANIFESTAÇÕES PATOLÓGICAS EXISTENTES EM RESIDÊNCIAS LOCALIZADAS NA CIDADE DE SOBRAL/CE
}

\author{
MELO, LEONARDO FLAMELL \\ Estudante \\ Universidade Estadual Vale do Acaraú \\ Ceará; Brasil \\ eng.leonardo@gmail.com
}

\author{
SALES, JUSCELINO CHAVES \\ Professor Doutor \\ Universidade Estadual Vale do Acaraú \\ Ceará; Brasil \\ juscelinochaves@hotmail.com
}

\section{RESUMO}

O presente trabalho buscou identificar as principais manifestações patológicas encontradas em habitações de um empreendimento na cidade de Sobral, com o total de 50 residências unifamiliares, afim de refletir sobre a qualidade da habitação de interesse social. Sabe-se que o surgimento de manifestações patológicas pode comprometer a estrutura e a vida útil das edificações, com isso o estudo utilizou a ferramenta de qualidade, matriz GUT, a qual torna-se importante pois analisa a gravidade, a urgência e a tendência de dados problemas e padroniza uma pontuação relacionada a priorização para a soluções destes. Dessa forma, ao utilizar da matriz GUT, conclui-se que as manifestações apresentadas nas unidades analisadas não tiveram pontuações com risco grave e imediato de reparo, sendo assim manutenções corretivas. A partir dos resultados foi possível contribuir significativamente com a qualidade construtiva de unidades habitacionais de novos empreendimentos, visando o desenvolvimento de técnicas e melhorias relacionadas com todas as etapas da construção civil.

Palavras-chave: manifestações patológicas, residências unifamiliares, matriz GUT.

\begin{abstract}
The present work aimed to identify the main pathological manifestations found in housing of a development in the city of Sobral, with a total of 50 single-family homes, in order to reflect on the quality of housing of social interest. It is known that the emergence of pathological manifestations can compromise the structure and the useful life of buildings, so the study used the quality tool, GUT matrix, which is important because it analyzes the severity, urgency and tendency of data problems and standardizes a prioritization score for their solutions. Thus, when using the GUT matrix, it was concluded that the manifestations presented in the units analyzed did not have scores with immediate and serious risk of repair, thus being corrective maintenance. From the results it was possible to contribute significantly to the construction quality of housing units of new projects, aiming at the development of techniques and improvements related to all stages of construction.
\end{abstract}

Keywords: pathological manifestations, single-family residences, GUT matrix.

\section{INTRODUÇÃO}

O setor da construção civil tem a engenharia civil como ciência ligada ao grande desenvolvimento de estudos e técnicas sobre as edificações no país que garantem melhorias relacionadas as etapas da construção civil. Porém, apesar do controle das tecnologias aliado a base teórica promoverem um monitoramento constante das edificações, desde a idealização do projeto até a concepção, diversas manifestações patológicas são recorrentes nas edificações.

Ferreira (2018) conclui que as incidências patológicas encontram-se diretamente relacionadas com o nível de controle de qualidade efetuado em cada um dos estágios do processo construtivo. E que o processo de manutenção em construções é fundamental, visto que pequenas manifestações patológicas quando previamente localizadas e tratadas podem impedir futuros problemas estéticos, funcionais e financeiros. 
As manifestações patológicas, congênitas (projetos), executivas (construção) ou do emprego de materiais inadequados, causam anomalias que interferem significativamente no bom desempenho das construções. Dessa forma, a sistemática de planejamento de todas as fases de um empreendimento tem papel fundamental para o produto final das edificações (IOSHIMOTO, 1988 apud Murari; Fioriti, 2013).

Nessa perspectiva, o presente trabalho teve como objetivo central identificar, de forma visual, as principais manifestações patológicas presentes em edificações residenciais, localizadas no loteamento Moradas da Boa vizinhança II na cidade de Sobral-CE.

Pretende-se, após identificá-las, utilizar a ferramenta de qualidade, Matriz GUT (Gravidade, Urgência, Tendência), como suporte de metodologia na análise dos fenômenos patológicos analisados e com isso obter uma ordem de priorização na solução dos danos encontrados e assim contribuir para o planejamento aplicado no processo de manutenções de novos empreendimentos de loteamento com unidades similares.

Dentre as análises deste estudo, constatou-se que a manifestação patológica mofos/bolores foi a primeira na lista de prioridade de manutenção com relação as adversidades analisadas neste estudo.

Ainda, os resultados demostraram que a aplicação da matriz GUT tornou-se efetiva nas análises das manifestações patológicas, servindo como classificação dos danos com suas respectivas prioridades, dessa forma pude se estabelecer uma sistemática de manutenção tanto corretiva quanto com a prevenção, garantindo redução de custos para a empresa.

Além disso, os resultados servirão para beneficiar a empresa detentora dos empreendimentos com informações acerca das principais ocorrências, possibilitando a realização de técnicas corretivas especificas. Utilizando-as previamente as ocorrência de manifestações patológicas comuns, concluindo que os problemas específicos, acarretados devido à falta de manutenção preventiva, sejam solucionados e assim evitando custos elevados posteriores com o tratamento e correção das manifestações patológicas.

O objetivo geral deste trabalho foi identificar/analisar as principais manifestações patológicas sistematicamente encontradas nas edificações de pequeno porte com o auxílio do método da Matriz GUT.

\subsection{Justificativa}

As manifestações patológicas estão visíveis em todas as fases da construção de uma edificação. Dessa forma, o estudo dos problemas patológicos que se manifestam nas edificações quando reconhecido na fase de origem contribui para que em obras futuras sejam tomadas medidas preventivas com o intuito de evitar manifestações patológicas, sabendo que estas trazem prejuízo financeiro quanto a manutenção corretiva. Para tal, é necessário que eles sejam claramente identificados e indicadas as causas prováveis, de forma a se estabelecer uma sistemática de prevenção.

Com isso, o presente trabalho que tem como objetivo central, realizar o levantamento das principais manifestações patologias encontradas nas edificações de pequeno porte, de um loteamento situado em Sobral/CE, e posteriormente a identificação, pretende-se aplicar o método da Matriz GUT e obter a sequência de priorização dos danos observados nas edificações analisadas.

A partir deste estudo, com base nos dados e considerações finais, pretende-se contribuir para a análise das causas das ocorrências de tais manifestações patológicas e assim incentivar o estudo e desenvolvimento de técnicas que possibilitam a redução destas incidências, trazendo redução dos custos com manutenção corretiva, um aumento do grau de satisfação dos usuários das edificações e melhorias relacionadas com todas as etapas da construção civil e assim minimizar os cuidados necessários nas fases futuras a entrega da construção.

\section{METODOLOGIA}

O método de pesquisa utilizado no presente trabalho foi inicialmente a pesquisa bibliográfica ou exploratória, onde buscou-se através de uma extensa leitura de obras de diversos autores procurou-se apresentar conceitos fundamentais sobre as manifestações patológicas das construções residenciais, além de dissertar acerca do método GUT, desde conceitos e aplicação da Matriz GUT. 
Conseguinte, foi iniciada a pesquisa experimental, através de um estudo de caso, onde foi realizado em 50 casas unifamiliares localizadas na quadra 21, do loteamento Moradas da Boa Vizinhança II, situado na cidade de Sobral/CE, no ano de 2019.

Para a obtenção dos resultados, foi realizado um check-list elaborado pela empresa, este foi aplicado simultaneamente ao momento da entrega da unidade residencial, firmando assim a entrega do imóvel para o cliente. Após a entrega das residências, o presente autor fez o levantamento das principais manifestações patológicas encontradas nas edificações, dados obtidos através do sistema de suporte pós-venda que a empresa oferece aos clientes.

Com isso, ao analisar o levantamento das ocorrências, o autor optou em aplicar o método GUT em 22 unidades residenciais das 50 analisadas. As edificações onde houve a aplicação da matriz GUT foram as que tiveram ocorrências que envolveram o aparecimento de manifestações patológicas.

O convívio diário e o acompanhamento constante das construções das edificações desde o planejamento até o pós-venda propuseram a obtenção dos dados, a interpretação e a organização dos dados. Além dos registros fotográficos para a identificação dos problemas patológicos.

\section{REFERENCIAL TEÓRICO}

\subsection{Primeiras edificações: evolução}

A evolução das habitações ocorreram em virtude do tempo, da influência da natureza, como a modificação dos solos e do clima e com as necessidades do Homem. Sabe-se que na história do homem pré-histórico as primeiras edificações eram chamados de abrigos naturais como as cavernas e grutas, estas serviam de refúgio do homem para se proteger do perigo dos animais e do clima.

O aparecimento das primeiras edificações não tem data conhecida. Porém, segundo Trindade (2014) a construção mais antiga de que se tem nota localiza-se na cidade de Jerusalém, em Israel. Trata-se da Cúpula do Rochedo, datada entre 685 e 691 D.C.

Para Branco (2005) e Lourenço (2013) as necessidades e o aprimoramento das técnicas as edificações foram surgindo e a evolução das edificações foi ocorrendo com o tempo. Como exemplo, eles ainda citam que, desde o aparecimento do Homem, a técnica e a arte de trabalhar a madeira têm evoluído, começando por um processo manual até à vasta engenhosa indústria moderna vista atualmente.

A partir destes conhecimentos adquiridos desde os primórdios, a forma de construir não difere do processo antigo. No Brasil, o grande crescimento do mercado da construção civil não foi diferente, na prática o setor da construção civil seguiu e evoluiu de acordo com as necessidades dos usuários.

No entanto, as habitação hoje tem critérios, normas e formalidades que estejam de acordo com a conformidade, a qualidade e assim possam garantir a segurança, conforto ao usuário. E com isso, o governo tem destinado órgãos para fiscalizar as novas construções, buscando garantir qualidade de vida para todos. Porém, sabe-se que o déficit habitacional é um ponto crítico, em sua totalidade para as classes de baixa renda. Borges \& Sabbattini (2008) explanam sobre incorporadoras e as construtoras brasileiras, que buscaram nos anos após 2007 seguir o segmento da construção civil como o grande mercado, com ênfase para a produção de um grande volume de habitações de interesse social.

Desse modo, o levantamento da qualidade das construções podem contribuir para o mapeamento da situação das edificação, bem como expor a dimensão do problema. Pois mesmo com os órgãos e programas criado pelo governo para resolver o problema habitacional, há inúmeras famílias sem habitação digna, algo que não condiz com a Constituição Brasileira, onde no Art. $6^{\circ}$ afirma que habitação é um direito básico de cidadania garantido entre os direitos sociais.

\subsection{Manifestações patológicas}

Entende-se que não cabe aqui apresentar uma revisão bibliográfica geral de todos os possíveis fatores que influenciam no aparecimento das manifestações patológicas, em virtude dos inúmeros trabalhos que apresentam o assunto com excelência e respaldo na literatura brasileira e internacional, abordando aspectos que possivelmente 
passariam despercebidos pelo autor deste trabalho, em função do foco do seu trabalho. Além disso, considera-se que, diante da existência de excelentes trabalhos na área, seria inoportuno apresentar uma revisão similar a outras já realizadas ou, até mesmo, inferior a estas. Diante disso, os fatores abordados nos tópicos abaixo são correlacionados as manifestações patológicas, contextualizados em conceitos básicos, origem e causas e por fim um estudo breve sobre as manifestações patológicas mais comuns nas edificações sobre a visão de alguns autores.

O termo patologia do grego (phatos, doença e logos, estudo) é conceituado e utilizado em inúmeras áreas da ciência. Surgiu primeiramente na Medicina, sendo utilizada para verificar e tratas alterações estruturais, respiratórias celulares e doenças modificadoras do organismo. E analogicamente, na Engenharia o termo foi utilizado para possíveis doenças de uma edificação.

É bem verdade que o estudo das manifestações patológicas no Brasil, com maior rigor científico vem se intensificando cada vez mais.

Já Souza e Ripper (2009) sobre as manifestações patológicas dizem que a causa das anomalias vão desde o envelhecimento natural da edificação, até mesmo a problemas causados na execução da obra, tais como falta de comunicação, irresponsabilidade dos profissionais e uso inadequado de materiais. Já para Geyer e Brandão (2007) alguns componentes das edificações tais como fundações, estruturas de concreto, alvenarias e revestimentos cerâmicos são os mais susceptíveis ao aparecimento de problemas.

A origem da patologia pode ser classificada em congênita, surgem na fase de projeto; construtiva, surgimento na fase de execução da obra; adquiridas, são as que aparecem durante a vida útil da edificação e são causadas pela exposição ao meio em que se inserem e por fim patologias acidentais, que são originaria por algum fenômeno atípico, como resultado de uma solicitação incomum (PEDRO et al., 2002).

Optou-se por elencar nessa pesquisa as principais manifestações patológicas mais comuns e facilmente encontradas no modelo de edificações analisada como amostra no presente estudo. Diante disso, buscou explanar sobre os defeitos que se manifestam na forma de fissuras, trincas, destacamento, mofo e umidades. Para Verçosa apud Braga (2010) dentre as diversas manifestações patológicas, os deslocamentos, o bolor e as fissuras são como as anomalias mais comuns em concreto.

\subsection{Matriz GUT}

O Método GUT (Gravidade, Urgência, Tendência) foi concebido por Kepner e Tregoe na década de 1980, com a finalidade de solucionar as adversidades de difíceis soluções nas indústrias americanas e japonesas. Com tal ferramenta é possível priorizar determinados problemas, categoriza-los e criando métricas racionais, afim de oferecer maior atenção àquele que possui maior risco (KEPNER; TREGOE, 1981).

Essa metodologia leva em consideração a Gravidade (G), a Urgência (U) e a Tendência (T) dos problemas detectados evoluírem. Para esta avaliação, o método dispõe do uso de pesos que são associados a cada dano inspecionado, a fim de definir graus de criticidade em relação aos problemas encontrados (BRANDÃO, 2018).

Meireles (2001) diz que em determinados problemas, durante a aplicação do método GUT, o pesquisador poderá proceder de modo gradual quanto à resolução destes, distinguindo quais contratempos terão priorização na ordem de soluções, objetivando ações preventivas e corretivas para a total eliminação dos problemas.

Na literatura, o método GUT integra outros ciclos de gestão, como o ciclo PDCA. Segundo Rocha (2013), a Matriz GUT está intimamente ligada à primeira fase do ciclo PDCA, (P) Planejar, tendo o planejamento como primordial para a solução do problema, já que esta serve propriamente para solucionar problemas significativos de forma coerente.

\subsubsection{Metodologia de aplicação}

A aplicação da Matriz GUT torna-se essencial para o reconhecimento da prioridade dos problemas. Quando aplicada na construção civil em determinação da priorização das soluções das manifestações patológicas encontradas em uma determinada estrutura ocasionar o escalonamento de problemas, identificando realmente as primeiras complicações a serem resolvidas. 
O método tem início com a listagem todos os problemas provenientes da edificação ou entidade de interesse. Em conseguinte, é necessário atribuir notas para cada problema elencado com atenção na Gravidade, Urgência e Tendência para todos os obstáculos.

Vale ressaltar que a aplicação de tal ferramenta pode trazer resultados significativos, como exemplo, o resultado torna-se a chave para uma gestão rápida entre os gestores, que muitas das vezes não sabe como iniciar, agora tem a matriz como ferramenta que estabelece a tomada de decisão. Dessa forma, as ações corretivas ou preventivas apresentam-se como prática comum das construções.

De acordo com Daychoum (2012) a metodologia para a aplicação da matriz GUT envolve uma pontuação para cada parâmetro de gravidade, urgência e tendência que varia de 1 a 5, onde 1 é uma manifestação patologia dita como sem gravidade e 5 é extremamente grave. E para finalizar, o valor do resultado de cada parâmetro é multiplicado e assim feita a priorização com o valor final.

\begin{tabular}{|c|c|c|c|c|}
\hline & $\begin{array}{c}\text { Gravidade } \\
\text { Consequências se } \\
\text { nada for feito. } \\
\end{array}$ & $\begin{array}{c}\text { Urgência } \\
\text { Prazo para tomada } \\
\text { de decisão. }\end{array}$ & $\begin{array}{c}\text { Tendência } \\
\text { Proporção do } \\
\text { problema no futuro. }\end{array}$ & \\
\hline Pontos & $\mathbf{G}$ & $\mathbf{U}$ & $\mathbf{T}$ & $\mathbf{G} \times \mathbf{U} \times \mathbf{T}$ \\
\hline 5 & $\begin{array}{c}\text { Os prejuízos ou } \\
\text { dificuldades são } \\
\text { extremamente graves. }\end{array}$ & $\begin{array}{l}\text { É necessária uma } \\
\text { ação imediata. }\end{array}$ & $\begin{array}{c}\text { Se nada for feito, o } \\
\text { agravamento da } \\
\text { situação será imediato. }\end{array}$ & $\begin{array}{c}5 \times 5 \times 5= \\
125\end{array}$ \\
\hline 4 & Muito Graves. & $\begin{array}{c}\text { Com alguma } \\
\text { urgência. }\end{array}$ & $\begin{array}{c}\text { Vai piorar em curto } \\
\text { prazo. }\end{array}$ & $\begin{array}{c}4 \times 4 \times 4= \\
64\end{array}$ \\
\hline 3 & Graves. & O mais cedo possível. & $\begin{array}{c}\text { Vai piorar em médio } \\
\text { prazo. }\end{array}$ & $\begin{array}{c}3 \times 3 \times 3= \\
27\end{array}$ \\
\hline 2 & Pouco Graves. & $\begin{array}{c}\text { Pode esperar um } \\
\text { pouco. }\end{array}$ & $\begin{array}{c}\text { Vai piorar em longo } \\
\text { prazo. }\end{array}$ & $\begin{array}{c}2 \times 2 \times 2= \\
8\end{array}$ \\
\hline 1 & Sem Gravidade. & Não tem pressa. & $\begin{array}{c}\text { Não vai piorar ou pode } \\
\text { até melhorar. }\end{array}$ & $\begin{array}{c}1 \times 1 \times 1= \\
1\end{array}$ \\
\hline
\end{tabular}

Fonte: Adaptado de DAYCHOUM, 2012.

Outros autores também expõe suas tabelas onde são feitas as principais definições e pontuações para os parâmetros. Como exemplo, Verzola, Marchiori e Aragon (2014) que ao aplicar a matriz GUT utilizam-se de três tabelas para cada parâmetro e suas definições do grau. A Tabela 2 é quanto à gravidade, onde considera os perigos e ameaças ao usufruidor e ao meio ambiente. E ainda identifica os principais graus que devem ser atribuídos na classificação das manifestações patológicas. Ao contrário do Daychoum (2012) estes autores utilizam de termo como Total e Alta, para classificar o grau em extremamente grave ou muito grave, como visto na primeira coluna da tabela 2.

Tabela 2 - Classificação GUT quanto à Gravidade

\begin{tabular}{c|c|c}
\hline GRAU & DEFINIÇÃO DO GRAU & NOTA \\
\hline $\begin{array}{c}\text { TOTAL } \\
\text { Extremamente } \\
\text { Grave) }\end{array}$ & $\begin{array}{c}\text { Risco de morte, Impacto irrecuperável com perda excessiva } \\
\text { de desempenho, Prejuízo financeiro muito alto. }\end{array}$ & 10 \\
\hline $\begin{array}{c}\text { ALTA } \\
\text { (Muito Grave) }\end{array}$ & $\begin{array}{c}\text { Perigo de lesão aos usuários, Danos recuperáveis ao meio } \\
\text { ambiente e à edificação. }\end{array}$ & 8 \\
\hline $\begin{array}{c}\text { MÉDIA } \\
\text { (Grave) }\end{array}$ & $\begin{array}{c}\text { Risco de saúde aos usuários ocasionado pela degradação de } \\
\text { sistemas, Avarias ao meio ambiente reversíveis, perda } \\
\text { financeira média. }\end{array}$ & 6 \\
\hline $\begin{array}{c}\text { BAIXA } \\
\text { (Pouco Grave) }\end{array}$ & $\begin{array}{c}\text { Sem risco de saúde aos usuários, Baixa degradação ao meio } \\
\text { ambiente, Necessidade de substituição de alguns sistemas, } \\
\text { Perda financeira baixa }\end{array}$ & 3 \\
\hline NENHUMA & $\begin{array}{c}\text { Sem risco de saúde ou plenitude física, mínima deterioração } \\
\text { do ambiente, Nenhum dano de valor }\end{array}$ & 1 \\
\hline
\end{tabular}

Fonte: Adaptada de VERZOLA, MARCHIORI E ARAGON, 2014. 

Tendência.

Ainda sobre os mesmos autores é visto na tabela 3 a definição do grau quando à Urgência e na 4 quanto à

Tabela 3 - Classificação GUT quanto à Urgência

\begin{tabular}{|c|c|c|}
\hline GRAU & DEFINIÇÃO DO GRAU & NOTA \\
\hline $\begin{array}{c}\text { TOTAL } \\
\text { (Extremamente } \\
\text { Urgente) } \\
\end{array}$ & $\begin{array}{l}\text { Acontecimento imediato, Necessidade de intromissão do } \\
\text { imóvel sem prazos extras. }\end{array}$ & 10 \\
\hline $\begin{array}{c}\text { ALTA } \\
\text { (Grande Urgência) }\end{array}$ & $\begin{array}{l}\text { Acontecimento na iminência de acontecer, urgente } \\
\text { intervenção. }\end{array}$ & 8 \\
\hline MÉDIA & $\begin{array}{l}\text { Adversidade prevista para breve, necessidade de intervir } \\
\text { rapidamente. }\end{array}$ & 6 \\
\hline BAIXA & $\begin{array}{l}\text { Inicialização de um incidente, intervenção ainda em forma de } \\
\text { planos. }\end{array}$ & 3 \\
\hline NENHUMA & $\begin{array}{l}\text { Adversidade imprevista, mas necessário acompanhamento } \\
\text { para futuras manutenções. }\end{array}$ & 1 \\
\hline
\end{tabular}

Fonte: Adaptada de VERZOLA, MARCHIORI E ARAGON, 2014.

Tabela 4 - Classificação GUT quanto à Tendência

\begin{tabular}{c|c|c}
\hline GRAU & DEFINIÇÃO DO GRAU & NOTA \\
\hline TOTAL & $\begin{array}{c}\text { Progresso da manifestação imediato, podendo haver pioras a } \\
\text { qualquer instante }\end{array}$ & 10 \\
\hline ALTA & $\begin{array}{c}\text { Evolução da situação prestes a ocorrer } \\
\text { MÉDIA }\end{array}$ & 8 \\
\hline BAIXA & Eossível evolução a longo prazo. Poderá vir a ocorrer, \\
Situação de demora. & 6 \\
\hline NENHUMA & Situação estabilizada, Sem evolução do caso. & 1 \\
\hline
\end{tabular}

Fonte: (Adaptada de VERZOLA, MARCHIORI E ARAGON, 2014).

É visto que a metodologia envolve a atribuição de pesos e posterior a distribuição destes, utiliza-se um cálculo simples de multiplicação. Pois torna-se necessário obter um número que consistirá no desfecho da verificação e assim estabelecer qual grau de preferência do problema, ou seja, a priorização da solução do problema. A tabela 5 mostra como pode ser feito a organização das manifestações patológicas em tabela, assim como, a prioridade de solução.

Tabela 5 - Tabela de prioridade e solução de tratamento

\begin{tabular}{c|c|c|c}
\hline $\begin{array}{c}\text { MANIFESTAÇÃO } \\
\text { PATOLÓGICA }\end{array}$ & PONTOS & PRIORIDADE & $\begin{array}{c}\text { MEDIDA } \\
\text { REPARATÓRIA }\end{array}$ \\
\hline Tipo de manifestação & $(\mathrm{G}) \mathrm{x}(\mathrm{U}) \mathrm{x}(\mathrm{T})$ & $\begin{array}{c}\text { Ordem decrescente de } \\
\text { pontuação }\end{array}$ & $\begin{array}{c}\text { Solução do } \\
\text { problema }\end{array}$ \\
\hline
\end{tabular}

Fonte: Autor, 2019.

A partir da tabela 5 encontra-se a organização das manifestações patológicas encontradas em uma determinada edificação em suas respectivas ordens de prioridade através de uma ordem decrescente de pontuação. Assim, o gestor conseguirá de maneira racional intervir e buscar soluções para as não conformidades bem como parâmetros ou fundamentos indispensáveis ao deparar-se em situações de risco.

\section{ESTUDO DE CASO}

O conjunto habitacional estudado está localizado no município de Sobral/Ce, em loteamento aprovado no ano de 2015, a 10km do centro da Cidade de Sobral. Loteamento esse que tem nome de Moradas da Boa Vizinhança II. A Figura 1 expõe a localização deste empreendimento, expresso na delimitação feita na cor azul. 


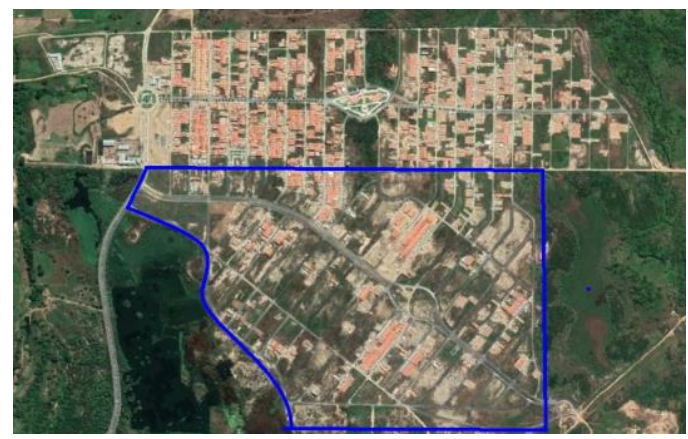

Fonte: Autor, 2019.

O projeto de implantação das edificações analisadas nesta pesquisa foram unidades residenciais localizadas da quadra 21 do loteamento expresso acima, sendo elas casas do tipo unifamiliar. A figura 2 expõe a localização exata destas.

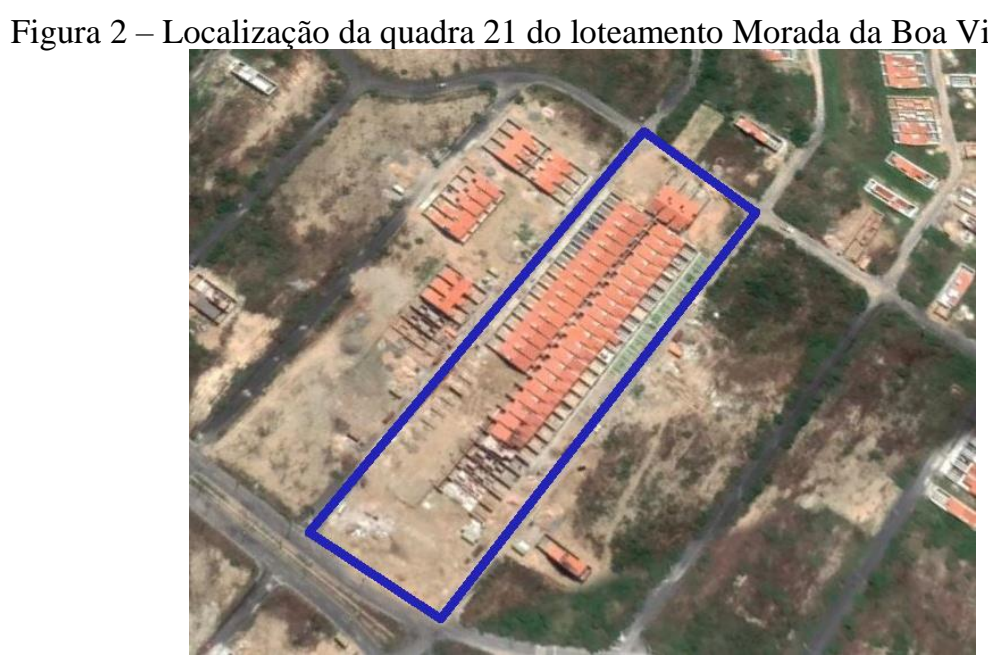

Fonte: Autor, 2019.

\subsection{Análise dos dados}

O levantamento das manifestações patológicas encontradas das residências analisadas foi feito no período de entrega da casa e no pós-venda, através de vistorias técnicas qualitativas por meio de observação direta após o registro da ocorrência feita parte dos usuários.

Nesta visita é realizado o registro fotográfico do problema encontrado, elencado as manifestações patológicas e estudado a melhor maneira de saná-las. No decorrer das análises, procedeu-se sempre a produção de uma documentação de declaração de reparo, registrando o estado final das unidades após a solução do problema.

O convívio diário e o acompanhamento constante das construções das edificações desde o planejamento até o pós-venda propuseram ao autor a identificação dos problemas patológicos mais frequentes entre as unidades do empreendimento. As figuras 3, 4 e 5 mostram algumas patologias encontradas nas edificações em análise neste estudo. 
Figura 3- Manifestação do tipo Fissura/Trincas encontrada na casa 4. (a) Fissuras internas na janela da sala (b) Fissuras externas localizada no quarto social.

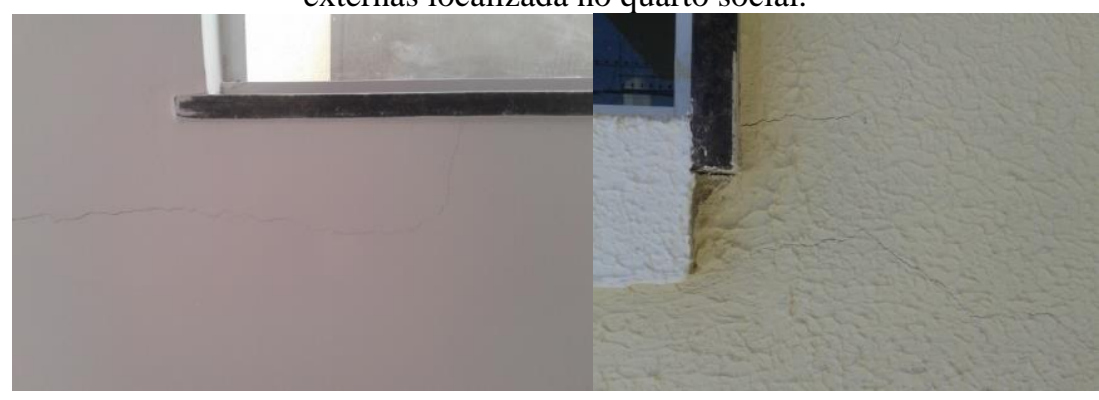

(a)

(b)

Fonte: Autor (2019).

Figura 4 - Manifestação do tipo Mofo/Bolores encontrada na casa 26. (a) Quarto social e (b) Parede da sala.

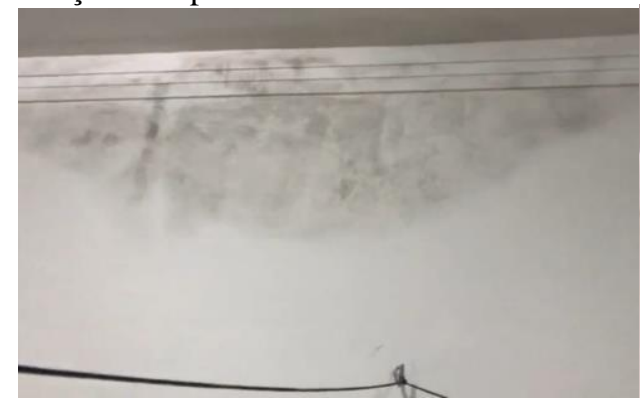

(a)

Fonte: Autor (2019).

(b)

Figura 5- Manifestações do tipo Desplacamento encontrado na casa 5. (a) Teto da sala e (b) Detalhe.

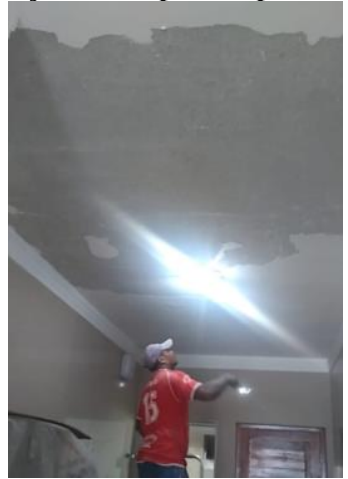

(a)

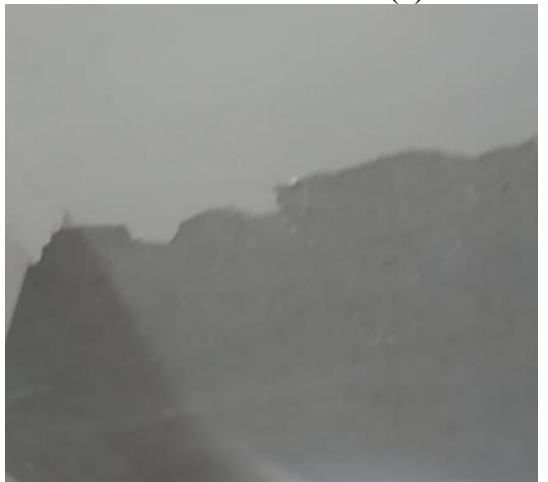

(b)

Fonte: Autor (2019).

\subsection{Aplicação da matriz GUT}

Após a obtenção dos dados, através dos correspondentes fotográficos e anotações em planilhas para documentação das ocorrências feitas pelos clientes, o autor optou em aplicar o método GUT em 22 unidades residenciais das 50 analisadas.

Unidades estas que tiveram ocorrências que envolveram o aparecimento de manifestações patológicas. As demais foram descartadas por não apresentarem ocorrências significativas para serem abordadas neste estudo.

As manifestações patológicas a serem analisadas foram: Fissuras/trincas, mofos ou bolores e desplacamentos. Estas foram tabuladas de acordo com as informações coletadas pelo autor no momento do registro da ocorrência feita pelo cliente. 
Como falado anteriormente, nestes dados foi aplicado a metodologia de priorização, método da matriz GUT, para a geração de um lista de priorização da solução dos problemas encontrados. Para gerar tais listas, utilizou-se planilhas eletrônicas Microsoft Office Excel (2007) para formulação de tabelas e gráficos nos quais possibilitou a emissão de conclusões, relacionando-os entre si. Da mesma forma, estes dados permitiram a quantificação das manifestações patológicas mais recorrentes nas amostras, e assim, a escolha em elencar as mais comuns tornou-se mais fácil.

\section{RESULTADOS E DISCUSSÕES}

Para os resultados desta pesquisa, optou-se por elencar algumas patologias consideradas mais comuns entre as amostras e que são facilmente encontradas nesse modelo de edificação. Dentre elas são: Fissuras e trincas, mofos ou bolores e desplacamentos. O gráfico 1 mostra a quantidade aparecimento destas manifestações entre as 50 casas estudadas.

Gráfico 1-Quantitativo das casas de acordo com o aparecimento dos 3 tipos de patologias.

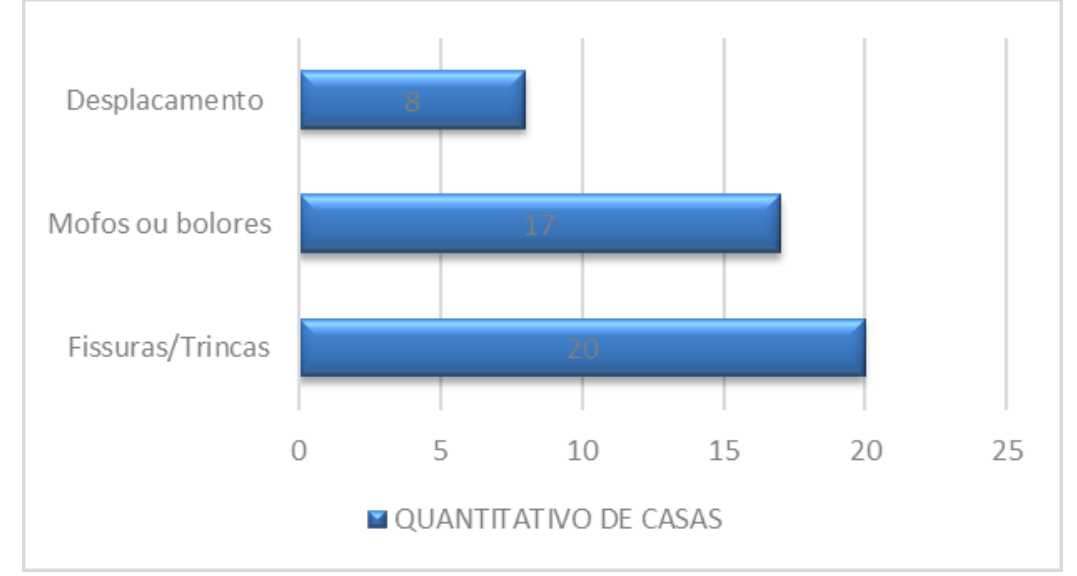

Fonte: Autor, 2019.

Ainda, com a análise dos dados, pode comparar o aparecimento dos três tipos de patologias na mesma residência, de pelo menos um dos tipos e o não aparecimento de nenhuma dos tipos de manifestações patológicas abortadas neste estudo (Gráfico 2).

Gráfico 2- Quantitativo do aparecimento de manifestações patológicas.

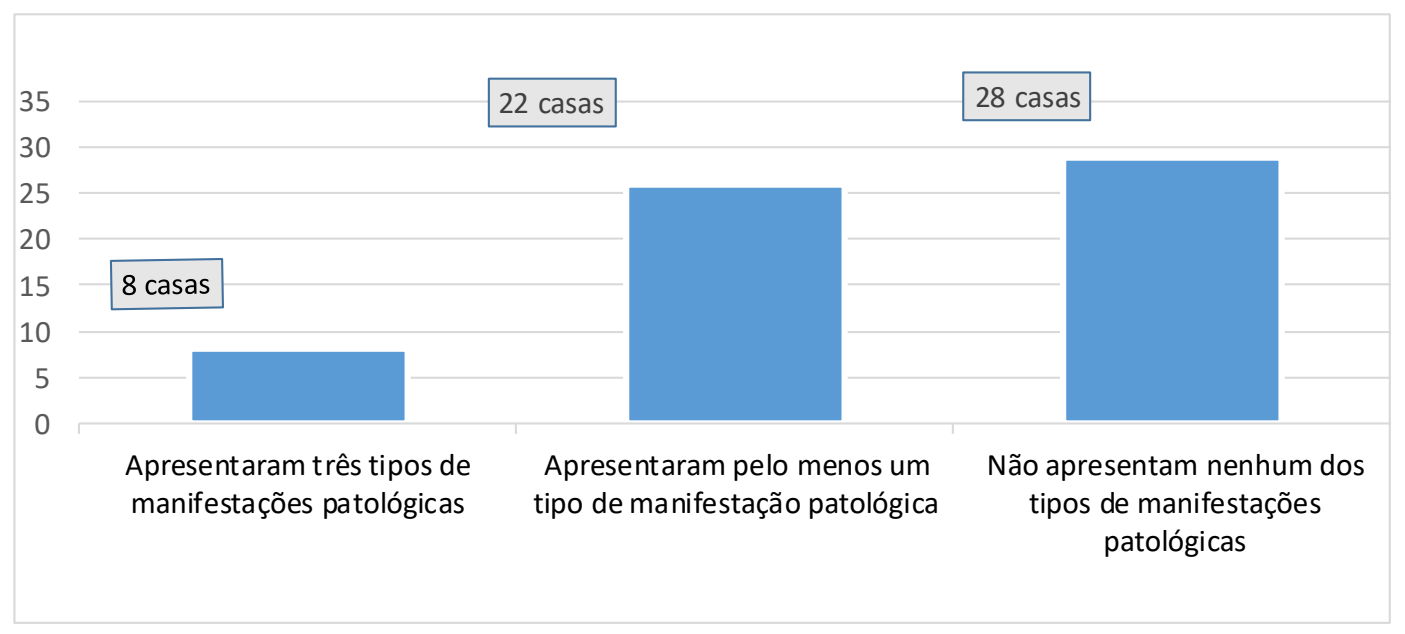

Fonte: Autor, 2019.

A partir dos resultados da figura acima, pode concluir que em 22 casas apresentaram pelo menos um dos tipos de manifestações. Com isso, foi feita a aplicação da matriz GUT para obter a elaboração da lista de prioridades na resolução dos problemas. A Figura 6 identifica e localiza as 22 unidades que tiveram a aplicação do método GUT. 
Figura 6 - Localização das 22 casas que tiveram a aplicação do método GUT.

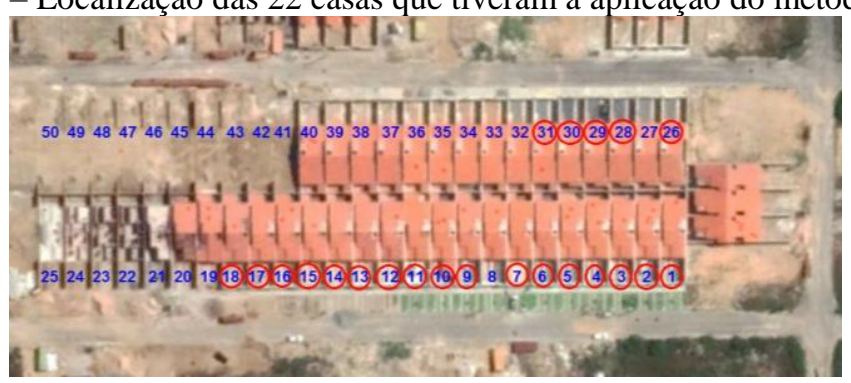

Fonte: Autor, 2019.

A partir da coleta de dados realizada por meio de registro fotográfico durante a vistoria e seguindo aplicação do método GUT das tabelas 2, 3 e 4, o presente autor aplicou tal metodologia e obteve a Tabela 6, esta apresenta a caracterização das manifestações patológicas nas respectivas casas analisadas, os valores propostos para cada parâmetro do método GUT e o valor resultante para cada edificação.

TABELA 6. APLICAÇÃO DA MATRIZ GUT NAS 22 CASAS.

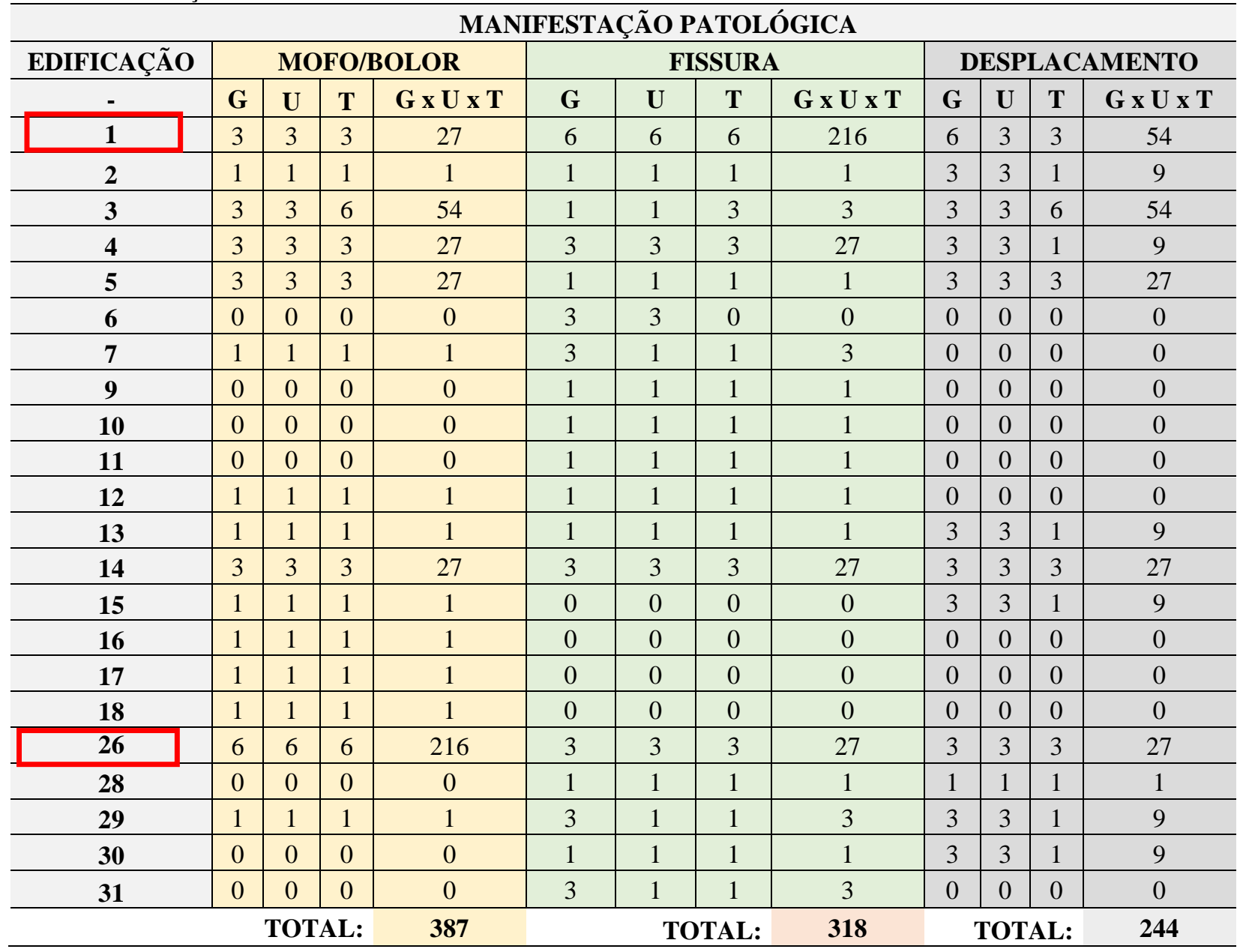

Fonte: Autor, 2019.

A partir dos resultados obtidos após a aplicação da matriz GUT, expresso na tabela 6 onde relatamos a pontuação de cada casa podemos observar que algumas destas tiveram pontuações superiores as demais, como destaque as casas 1 e 26 com ênfase para o aparecimento de fissuras e mofo/bolores, respectivamente. 
E quanto ao grau de prioridade na resolução dos problemas, o autor realizou o somatório da pontuação de todas as casas analisadas sobre os mesmo tipos de manifestações patológicas, de acordo com o modelo expresso na tabela 7.

Tabela 7 - Modelo da Tabela de prioridade

\begin{tabular}{c|c|c}
\hline $\begin{array}{c}\text { MANIFESTAÇÃO } \\
\text { PATOLÓGICA }\end{array}$ & PONTOS & PRIORIDADE \\
\hline Tipo de manifestação & SOMATÓRIO $=(\mathrm{G}) \times(\mathrm{U}) \mathrm{x}(\mathrm{T})$ & $\begin{array}{c}\text { Ordem decrescente de } \\
\text { pontuação }\end{array}$ \\
\hline
\end{tabular}

Fonte: Autor, 2019.

Com isso, os resultados na Tabela 8 apresentam do somatório e assim a lista de prioridade das manifestações patológicas, estes valores foram organizados de forma decrescente.

TABELA 8. PONTUAÇÃO DE PRIORIZAÇÃO PARA SOLUÇÃO DAS QUANTO AS MANIFESTAÇÕES PATOLÓGICAS.

\begin{tabular}{c|c|c|}
\hline MANIFESTAÇÃO PATOLÓGICA & $\mathbf{N}^{\mathbf{0}}$ DE PONTOS & $1^{\mathbf{0}}$ \\
\hline MOFO/BOLOR & 387 & $2^{\mathbf{o}}$ \\
\hline FISSURA & 318 & $3^{\mathbf{0}}$ \\
\hline
\end{tabular}

Fonte: Autor, 2019.

Pode-se constatar que as manifestações patológicas mofos/bolores apresentaram maior necessidade de urgência. Estas manifestações foram verificadas em 17 edificações das 50 analisadas e demonstraram um maior risco a saúde e segurança dos usuários.Foi possivel justificar que o aparecimento de infiltrações nestas unidades familiares propuseram o aparecimento de tais patologias.

A priorização realizada dessa forma guia a realização de manutenção conjunta em todas as edificações visitadas, de acordo com as manifestações patológicas localizadas no topo da lista.

Diante disso, conclui-se que a ferramenta GUT pode ser aplicada como facilitadora do planejamento das atividades de manutenção em, com base nos resultados e na avaliação proposta.

\section{CONCLUSÕES}

Após a identificação das manifestações patológicas, foi observado que $44 \%$ das 50 casas analisadas apresentaram pelo menos uma das manifestações patológicas estudadas e nestas foram aplicados o método GUT.

Com a utilização da Matriz GUT (Gravidade, Urgência, Tendência), foi obtido uma ordem de priorização na solução dos danos encontrados de forma decrescente, sendo mofos e bolores o primeiro com relação as demais adversidades analisadas. Dessa forma, a lista de priorização serviu de guia para a realização de manutenção conjunta em todas as edificações visitadas, de acordo com as manifestações patológicas localizadas no topo da lista.

Mostraram ainda que, dentre as manifestações patológicas identificadas não envolviam a manutenção corretiva dos elementos estruturais das unidades residenciais.

Ainda, a partir das informações pôde-se perceber que os problemas específicos foram acarretados devido à falta de manutenção preventiva. Com isso, o levantamento a partir da identificação das principais manifestações patológicas encontradas serviram para evitar custos elevados com o tratamento e correção das manifestações.

E sobre a mesma perspectiva, dentre os resultados obtidos no presente trabalho, constatou-se que os resultados servirão para beneficiar a empresa detentora dos empreendimentos com informações acerca das principais ocorrências, possibilitando a realização de técnicas corretivas especificas e a aplicação de um planejamento no processo de manutenções de novos empreendimentos no loteamento com unidades similares.

E quanto a matriz GUT, os resultados demostraram que a aplicação do método tornou-se efetivo para a análise patológica, servindo como classificação dos danos com suas respectivas prioridades, dessa forma pôde-se estabelecer uma sistemática de manutenção tanto corretiva quanto preventiva, garantindo redução de custos para a empresa. 
Por fim, conclui-se que o presente trabalho referente a aplicação do método da Matriz GUT em edificações unifamiliares mostra-se muito relevante e constitui uma ferramenta de suporte na gestão da manutenção de edificações, contribuindo para a conservação e a segurança das estruturas, bem como ao conforto dos usuários.

\section{REFERÊNCIAS}

ASSOCIAÇÃO BRASILEIRA DE NORMAS TÉCNICAS (ABNT). NBR 15575-5: Edificações habitacionais Desempenho. Rio de Janeiro: ABNT, 2013.

BRANDÃO, F. et al. Dynamic characterization of a heritage construction from 19th century. Revista Ibracon de Estruturas e Materiais, v. 11, n. 1, p.52-75, fev. 2018.

KEPNER, C. H.; TREGOE, B. B. O administrador racional. São Paulo: Atlas, 1981. P 58.

BRAGA, C. C. Manifestações Patológicas em Conjuntos Habitacionais: A Degradação das Fachadas. 2010. 158 f. Dissertação de Mestrado (Trabalho de Conclusão de Curso de Engenharia Civil). - Universidade Católica de Pernambuco, Recife, 2010.

BORGES, C. A. M.; SABBATTINI, F. H. O conceito de desempenho de edificações e a sua importância para o setor da construção civil no Brasil. São Paulo: EPUSP, 2008.

DAYCHOUM, M. Ferramentas e técnicas de gerenciamento. Rio de Janeiro: Brasport, 2012.

GEYER, André Luiz Bortolacci. BRANDÃO, Rosana Melo de Lucas. Patologia nas

Edificações, com até Cinco Anos de Idade, Executadas no Estado de Goiás.Goiânia, 2007, 136p.

SILVEIRA NETO, O. Manifestações patológicas em condomínios habitacionais de interesse social do município de Porto Alegre: Levantamento e estudo sobre a recorrência. Dissertação (Mestrado em Engenharia): Universidade Federal do Rio Grande do Sul - UFRGS, Porto Alegre, 2005.

IOSHIMOTO, E. Incidência de manifestações patológicas em edificações habitacionais. In: Tecnologia de edificações, 1988, São Paulo: Pini. P. 545 - 548.

PEDRO, J.B. Definição e avaliação da qualidade arquitectónica habitacional. Tese de doutorado. Faculdade de arquitetura, Universidade do Porto, Lisboa,2002.

TRINDADE, L. V. de P. Evolução da arquitetura e dos materiais para cobertura de edificações. Aecweb: Arquitetura, Construção e Engenharia, 2014.

SOUZA, V. C.M.; RIPPER, T. Patologia, recuperação e reforço de estruturas de concreto. São Paulo: Pini, 1998.

MEIRELES, M. Ferramentas administrativas para identificar, observar e analisar problemas: organizações com foco no cliente. São Paulo: Arte \& Ciência, 2001. 144 p. 